


\title{
Análisis del gasto corriente en los municipios rurales de Michoacán, México, 2001-2015
}

René Colín Martínez y Hugo Amador Herrera Torres

\author{
UNIVERSIDAD AUTÓNOMA DE CIUDAD JUÁREZ \\ PUBLICACIÓN AFILIADA A LA \\ RED IBEROAMERICANA DE ESTUDIOS DEL DESARROLLO
}




\title{
UNIVERSIDAD AUTÓNOMA DE CIUDAD JUÁREZ
}

\author{
PUBLICACIÓN AFILIADA A LA \\ RED IBEROAMERICANA DE ESTUDIOS DEL DESARROLLO
}

\section{Universidad Autónoma de Ciudad Juárez}

2018-2024

Mtro. Juan Ignacio Camargo Nassar

Rector

Mtro. Daniel Alberto Constandse Cortez

Secretario General

Mtro. Santos Alonso Morales Muñoz

Director del Instituto de Ciencias Sociales y Administración

Mtro. Jesús Meza Vega

Director General de Comunicación Universitaria

Comité de Coordinación de la Red Iberoamericana de Estudios del Desarrollo 2018-2020

Dra. Paulina Sanhueza Martínez (Universidad de la Frontera, Chile)

Coordinadora General

Dr. Ignacio Rodríguez Rodríguez (Universidad de la Frontera, Chile)

Secretario general

Dra. Myrna Limas Hernández

(Universidad Autónoma de Ciudad Juárez, México)

Vocal de Organización

Dr. Pablo Galaso Reca (Universidad de la República, Uruguay)

Vocal de Organización

Dr. Luis Enrique Gutiérrez Casas

Director y editor de Cuadernos de Trabajo

Estudios Regionales en Economía, Población y Desarrollo

Comité editorial

Sección internacional Dra. Sofía Boza Martínez

(Universidad de Chile, Chile)

Dra. Olga Biosca Artiñano

(Glasgow Caledonian University, Reino Unido)

Dra. Ángeles Sánchez Díez

(Universidad Autónoma de Madrid, España)

Dr. Thomas Fullerton Mankin

(University of Texas at El Paso, Estados Unidos)

Dr. Adrián Rodríguez Miranda

(Universidad de la República, Uruguay)

Dra. Ikuho Kochi

(Kanazawa University, Japón)

Sección local

(Universidad Autónoma de Ciudad Juárez)

Dra. Myrna Limas Hernández

Dra. Rosa María García Almada

Dr. Raúl Alberto Ponce Rodríguez

Dr. Isaac Leobardo Sánchez Juárez

Dr. Héctor Alonso Barajas Bustillos

Dr. Juan Carlos Medina Guirado

Diseño de cubierta Abigail Bautista
Estudios Regionales en Economía, Población

y Desarrollo. Cuadernos de Trabajo de la UACJ

ISSN 2007-3739

Número 61. Enero - Febrero 2021

Análisis del gasto corriente en los municipios rurales de

Michoacán, México, 2001-2015

René Colín Martínez y Hugo Amador Herrera Torres

Universidad Autónoma de Ciudad Juárez

Estudios Regionales en Economía, Población y Desarrollo.

Cuadernos de Trabajo de la UACJ

Año 11, No. 61 Enero - Febrero 2021, es una publicación bimestral editada por la Universidad Autónoma de Ciudad Juárez a través del Cuerpo Académico de Estudios Regionales en Economía, Población y Desarrollo del Instituto de Ciencias Sociales y Administración. Redacción: Avenida Universidad y H. Colegio Militar, Zona Chamizal s/n., C.P. 32300, Ciudad Juárez, Chihuahua, México.

Teléfonos: (656) 688-38-00, ext.3792. Correo electrónico: igtz@uacj.mx. Editor responsable: Luis Enrique Gutiérrez Casas. Reserva de derechos al uso exclusivo: edición impresa, ISSN 2007-3739., edición digital, No. de reserva 04-2019-050218151500. Impresa por Studio Los Dorados, calle Del Campanario, número 820-2, Santa Cecilia, C.P. 32350, Cd. Juárez, Chihuahua. Distribuidor: Subdirección de Gestión de Proyecto y Marketing Editorial. Ave. Plutarco Elías Calles 1210, Foviste Chamizal, C.P. 32310, Ciudad Juárez, Chihuahua. Este número se terminó de imprimir el 15 de noviembre 2020 con un tiraje de 120 ejempares.

Los ensayos publicados son responsabilidad exclusiva de sus autores.

Se autoriza la reproducción total o parcial bajo condición de citar la fuente.

\section{Registrada en: EBSCO RePEC}

Publicación afiliada a la Red Iberoamericana de Estudios del Desarrollo

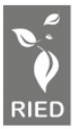

Universidad Autónoma de Ciudad Juárez

Ave Plutarco Elías Calles 1210

Foviste Chamizal, C.P. 32310

Ciudad Juárez, Chihuahua, México

www.uacj.mx

(C) Universidad Autónoma de Ciudad Juárez 


\title{
Análisis del gasto corriente en los municipios rurales de Michoacán, México, 2001-2015
}

\author{
René Colín Martínez * y Hugo Amador Herrera Torres **
}

\begin{abstract}
Resumen
El presente artículo intenta mostrar, calculando el efecto valor de origen, que el gasto corriente de los gobiernos de los municipios rurales del estado de Michoacán, México, es más elástico cuando se financia con transferencias federales que cuando los recursos provienen de fuentes propias. En los municipios rurales de Michoacán la proporción gasto corriente respecto a egresos totales es mayor que la relación de ingresos propios respecto a ingresos totales. En el artículo se plantea que el camino hacia la solución está en incrementar los recursos de fuentes propias a través de la innovación interna de las mismas municipalidades en materia de recaudación local, y a largo plazo en aumentar las potestades tributarias locales. Por sus características, no es prudente regular la proporción de gasto corriente financiado con recursos propios,
\end{abstract}

Palabras clave: Gasto corriente, ingresos propios, transferencias federales, efecto valor origen.

\begin{abstract}
This paper aims to prove, through the calculation of "efecto valor de origen", that the current expenditure of the governments of the semi-urban municipalities in Michoacán is more elastic when it's financed with federal transfers. Current expenditures tend to grow when increase federal transfers. Growth of current expenditures is faster than own income. In these governments, the ratio of current expenditure to total expenditure is much larger than the ratio of own resources to total revenues. The article states that the path to the solution is to increase the resources of their own sources through the internal innovation of the same municipalities in local collection, and in the long term in increasing local tax powers. Because of its characteristics, it is unwise to regulate the proportion of current expenditure financed by own resources.
\end{abstract}

Key words: Current expenditure, own revenues, federal transfers.

JEL: $H 70,018,054$

Recibido en: mayo de 2020.

Aprobado en: septiembre de 2020.

\footnotetext{
* Profesor de la Facultad de Economía de la Universidad Michoacana de San Nicolás de Hidalgo (México). Integrante del Cuerpo Académico de Economía, recursos naturales y planeación del desarrollo local sustentable. Correo electrónico: rcolin@fevaq.net.

** Profesor de la Facultad de Economía de la Universidad Michoacana de San Nicolás de Hidalgo (México). Integrante del Cuerpo Académico de Economía, recursos naturales y planeación del desarrollo local sustentable. Correo electrónico:hugoht@fevaq.net.
} 


\section{$\rightarrow$ 1. Introducción.}

De acuerdo con la tipología municipal de Herrera (2011: 83-111), Michoacán cuenta con 52 municipios rurales. Los municipios rurales en Michoacán dependen -en gran medida- de las transferencias federales, sus ingresos propios son bajos con respecto a sus ingresos totales, siendo de tan sólo $8 \%$ en promedio (en los municipios muy urbanos esta razón financiera se ubica entre el 25 y $31 \%$, y en los municipios semi-urbanos tiene un promedio de $12 \%$ ).

Esta situación ha contribuido a ensanchar el gasto corriente, lo que no ha ocurrido en otros rubros de egresos. El monto de las proporciones de gasto corriente es alto, oscilando entre el 37 y $66 \%$, con una media de 52\%. El municipio con la mayor proporción de gasto corriente es Tepalcatepec (66), el mínimo es Charapan (37\%).

El objetivo del presente artículo consiste en determinar que el gasto corriente es más elástico en los gobiernos de los municipios rurales de Michoacán cuando es cubierto con ingresos transferidos. En otras palabras, se estimará el efecto valor de origen para los municipios en cuestión. ${ }^{1}$ Este efecto se desprende del efecto mata moscas. El efecto valor de origen postula que los gobiernos subnacionales realizan un gasto más eficiente cuando los recursos provienen de ingresos propios y no de transferencias federales.

El artículo se integra de tres partes. La primera revisa el efecto flypaper y el efecto valor de origen, así como el federalismo hacendario y las transferencias directas de recursos. La segunda presenta la conformación de la Hacienda Municipal en Michoacán y las diversas fuentes de ingresos de los gobiernos locales, así como los rubros donde los gastan. La tercera corresponde al estudio empírico. Con el cálculo de elasticidades -con un modelo econométrico con datos de panel, complementado con la fórmula de elasticidades-, se comparó el grado de variación del gasto corriente al solventarlos con ingresos propios o con participaciones federales. Al final se muestran las conclusiones y la bibliografía utilizada. ${ }^{2}$

\footnotetext{
${ }^{1} \mathrm{El}$ antecedente directo del efecto valor de origen se halla en el trabajo de López (2004).

${ }^{2}$ Se usan, en este documento, como sinónimos los términos de gobierno municipal, gobierno local y municipalidades.
} 


\section{$\Rightarrow$ 2. El efecto Flypaper y el valor de origen.}

\subsection{El efecto matamoscas y el efecto valor de origen.}

Una revisión de la literatura muestra que el gasto en los gobiernos subnacionales tiende a responder más a recursos provenientes de transferencias intergubernamentales que a recursos recaudados de fuentes propias. Esto se conoce como el "efecto matamoscas", inicialmente nombrado por Arthur Okun, el dinero se "pega allí donde se posa" (Courant et al, 1979; Hines y Thaler, 1995; Kalb, 2010; Inman 2009, Sour, 2013).

Este efecto puede deberse a varias razones, entre las que sobresale el que los funcionarios locales intentan maximizar su presupuesto con base en su propia función de utilidad y de la comunidad; a que los ciudadanos no perciben el verdadero valor de los bienes públicos recibidos cuando son financiados con transferencias, por lo que el gasto tiende a ser mayor al óptimo; también a que si los gobiernos reciben recursos adicionales, los ciudadanos no se enteran inmediatamente y/o no tienen los medios necesarios para obligar al gobierno a que les regrese parte de sus impuestos; $y$, una vez creados, es difícil eliminar programas, incluso si las transferencias ya no existen, debido a los costos políticos que implican.

López (2004: 30) tomando como fundamento teórico el efecto mata moscas construyó el efecto valor de origen, el cual señala que los gobiernos sub-nacionales realizan un gasto más eficiente cuando los recursos provienen de ingresos propios y menos eficiente cuando se financia con transferencias federales.

\subsection{El federalismo en México.}

A inicios del siglo XX México contaba con un sistema tributario que permitía que los gobiernos locales recaudaran una proporción significativa de sus ingresos totales. En contraparte, dicho sistema tributario se caracterizaba por su gran complejidad, por la existencia de gran número de tributos y por la permanencia de la concurrencia impositiva o múltiple tributación.

La múltiple tributación no está prohibida por la Constitución de 1917, pero genera ineficiencia, por lo que hubo necesidad de solucionar esta situación. Los primeros intentos por eliminar la múltiple tributación se encuentran en las tres Convenciones Nacionales Fiscales, verificadas en 1925, 1933 y 1947 respectivamente. Gradualmente los gobiernos locales fueron cediendo la mayor parte de sus tributos a la Federación, a cambio de que ésta les compartiera parte de los recursos recaudados. Aun así, no se contaba con un sistema fiscal nacional debidamente coordinado, por lo que el esfuerzo para lograrlo se concretizó en 1979, con la formalización del 
Sistema Nacional de Coordinación Fiscal (SNCF) y la Ley Nacional de Coordinación Fiscal correspondiente, las que entraron en vigor a partir del primero de enero de 1980.

La creación del SNCF prácticamente eliminó el problema de la concurrencia impositiva, permitiendo así que muchos gobiernos locales cuenten con los recursos que les permiten mejorar el nivel de bienestar sus ciudadanos, accediendo a bienes y servicios que de otra forma estarían fuera de su alcance. Este sistema es dinámico, se ha ido mejorando constantemente. Destacan los cambios aplicados en 1997 con la creación del ramo 33 (aportaciones federales), y las reformas de 2007 y 2014.

Así, las principales maneras de transferir los recursos recaudados a repartir a los gobiernos locales son las participaciones federales y las aportaciones federales. Las participaciones federales, también llamadas Ramo 28, se distinguen porque son de libre aplicación, según el plan de desarrollo de la entidad federativa o municipio que corresponda; en tanto que las aportaciones federales o Ramo 33, son recursos que se diferencian de las participaciones federales porque son condicionados, no pueden aplicarse donde los gobiernos locales lo determinen.

Sin embargo, no todo ha sido bueno. La puesta en marcha del SNCF y su evolución han traído también problemas, generándose desequilibrios verticales y horizontales. En este artículo, se dará mayor interés a los desequilibrios verticales, debido a que éstos son resultado de la operación de SNCF. En otras palabras, el surgimiento y marcha del Sistema ha propiciado que el gobierno federal asuma los tributos que más aportan a la recaudación, dejando en el ámbito subnacional tributos poco eficientes, ocasionando que a nivel federal se recaude la mayor parte de los recursos. Esto ha llevado a los gobiernos locales a depender casi en su totalidad de los recursos provenientes de las transferencias federales, presentando graves problemas de autonomía financiera, así como grandes ineficiencias en el lado del gasto.

\section{O 3. Las finanzas en los municipios de Michoacán.}

\subsection{Ingresos municipales.}

La hacienda municipal se refiere al conjunto de recursos patrimoniales y económicos con que cuenta el gobierno local para realizar sus funciones (INAFED, s/f: 59). Los recursos, para el caso de los municipios de Michoacán, corresponden a dos rubros:

i. Los bienes muebles e inmuebles detallados en la Ley Orgánica Municipal. 
ii. Los ingresos que señalan la Ley de Hacienda Municipal, la Ley de Ingresos Municipales y las leyes de coordinación fiscal federal y estatal. Se trata en conjunto de impuestos, derechos, contribuciones de mejoras, productos, aprovechamientos, participaciones en ingresos federales, aportaciones federales y estatales, transferencias federales y estatales por convenio, apoyos extraordinarios, y financiamientos. Los municipios tienen ingresos además por disponibilidades iniciales (dinero que no fue gastado el año anterior) (véase cuadro 1).

Las participaciones federales se caracterizan por ser de uso no condicionado, los municipios las pueden usar para los fines que consideren convenientes, de acuerdo con la normatividad establecida y el plan de desarrollo correspondiente. Las participaciones federales van primero de la federación hacia el estado, luego el estado debe transferir al menos el $20 \%$ del total recibido hacia sus municipios, con los criterios que el mismo gobierno defina.

Cuadro 1

\section{Fuentes de ingresos municipales}

\begin{tabular}{|c|c|}
\hline \multirow{7}{*}{$\begin{array}{l}\text { 1. Ingresos } \\
\text { propios }^{3}\end{array}$} & -Impuestos a los ingresos, al patrimonio y accesorios. \\
\hline & -Cuotas y aportaciones de seguridad social. \\
\hline & $\begin{array}{l}\text {-Derechos. Pagos uso, goce aprovechamiento o explotación de bienes de dominio } \\
\text { público, por prestación de servicios, y otros. }\end{array}$ \\
\hline & $\begin{array}{l}\text {-Productos. Pagos recibidos por la enajenación o arrendamiento de bienes } \\
\text { patrimoniales, rendimientos de capital, venta de formas valoradas. }\end{array}$ \\
\hline & $\begin{array}{l}\text {-Aprovechamientos. Multas, recargos, gastos de ejecución, reintegro, } \\
\text { indemnizaciones. }\end{array}$ \\
\hline & -Contribución de mejoras. Cobros por beneficios derivados de la obra pública. \\
\hline & -Disponibilidad inicial. \\
\hline \multirow{4}{*}{$\begin{array}{l}\text { 2.Participaciones } \\
\text { federales } y \\
\text { estatales }\end{array}$} & -Fondo Participable. \\
\hline & -Fondo Estatal para la Infraestructura de los Servicios Públicos Municipales. \\
\hline & -Fondo de gasolinas y diésel \\
\hline & -Fondo de Fomento Municipal. \\
\hline \multirow{2}{*}{$\begin{array}{l}\text { 3. Aportaciones } \\
\text { federales }\end{array}$} & -Fondo de Aportaciones para la Infraestructura Social Municipal (FAISM). \\
\hline & -Fondo de Aportaciones para el Fortalecimiento de los Municipios. \\
\hline \multirow{3}{*}{ 4. Otros } & -Transferencias federales y estatales por convenio. \\
\hline & -Apoyos extraordinarios. \\
\hline & -Ingresos extraordinarios (financiamiento). \\
\hline
\end{tabular}

Fuente: elaboración propia con base en la Ley de Hacienda Municipal, Ley de Ingresos Municipales y leyes de coordinación fiscal federal y estatal.

\footnotetext{
${ }^{3}$ En la Ley de Ingresos Municipal se fijan las cuotas, tasas y tarifas para cada fuente de ingresos propios.
} 
La cuantía que reciben los municipios por participaciones depende de varios fondos (véase cuadro 1), pero está determinada principalmente por la cantidad de recursos que reciba la entidad federativa por este ramo. El monto de las participaciones que reciben los estados en México depende de:

i. Transferencias recibidas hasta 2007. Hasta ese año, las fórmulas no incluían criterios de eficiencia. El 45.17\% se recibía con base en el número de habitantes, otro porcentaje igual se recibía según la eficiencia en la recaudación, y el resto de manera inversa a los dos anteriores.

ii. A partir de 2008 y derivado de la reforma de 2007, cada estado recibiría al menos lo mismo que en 2007, y de haber recursos adicionales, éstos se transferirían considerando las siguientes expresiones establecidas en la Ley Nacional de Coordinación Fiscal:

$$
P_{i, t}=P_{i, 07}+F G P_{07, t}\left(0.6 C 1_{i, t}+0.3 C 2_{i, t}+0.1 C 3_{i, t}\right)
$$

Donde $\mathrm{P}_{\mathrm{i}, \mathrm{t}}$ corresponde al monto total de participaciones; $\mathrm{P}_{\mathrm{i}, 07}$ a las participaciones que recibían las entidades federativas hasta $2007 ; \Delta \mathrm{FGP}_{07, \mathrm{t}}$ es el monto adicional que se asigne a partir de 2008, el cual se distribuirá con base en tres criterios:

i. C1 (60\%) se asigna con base en el esfuerzo para incrementar el PIB en el año anterior, respecto al esfuerzo que hicieron todos los estados (se considera el esfuerzo relativo).

ii. C2 (30\%) se determina con base en el esfuerzo para incrementar la recaudación local de impuestos y derechos, utilizando un promedio móvil de los últimos tres años. Este esfuerzo es también relativo, comparado con lo hecho por las demás entidades federativas.

iii. C3 (10\%) se calcula con base en la participación de la entidad en el total recaudado por las entidades federativas por los conceptos de impuestos y derechos.

En Michoacán, la manera concreta de transferir los recursos a los municipios se establece en la Ley Estatal de Coordinación Fiscal para cada año. El gobierno del estado reparte el 20\% de las participaciones recibidas. En el caso de 2018 se consideran 3 fondos, el Fondo Participable, el Fondo de Gasolinas y Diésel y el Fondo Estatal para la Infraestructura de los Servicios Públicos Municipales:

i. El Fondo Participable (FP) se integra con tres cantidades: 
a) 20\% de lo que corresponda a la entidad en los siguientes fondos e impuestos:

- Fondo General de Participaciones (FGP).

- Fondo de Fiscalización y Recaudación (FFR).

- Impuesto Especial sobre Producción y Servicios (IEPS).

- Impuesto sobre Automóviles Nuevos (ISAN).

- Impuesto sobre Tenencia y Uso de Vehículos (ITUV).

- Fondo de Compensación por Incremento en la Exención del Impuesto sobre Automóviles Nuevos (FCISAN).

b) $100 \%$ del Fondo de Fomento Municipal (FFM).

c) $80 \%$ de los ingresos que perciba la entidad del Impuesto sobre Loterías, Rifas, Sorteos y Concursos (ILRSC).

La fórmula que integra las tres cantidades es:

$$
F P=((F G P+F F R+I E P S+I S A N+I T U V+F C I S A N) * 0.2)+F F M+(I L R S C * 0.8)
$$

Del total a repartir por el FP -exceptuando el FFM-, El 45\% se distribuye según el número de habitantes de cada municipio; otro $45 \%$ con base en el coeficiente de desarrollo relativo municipal; el 10\% restante se distribuye de manera inversa al número de habitantes.

ii. El Fondo de Gasolinas y Diésel (FGIIP) se integra por el 20\% de lo que corresponde al estado en función de la recaudación del Impuesto a la Venta de Gasolinas y Diésel (IVFGD), efectuado en el territorio de la entidad, y el 20\% de lo que corresponde al estado del Fondo de Compensación, derivado del Impuesto a la Venta de Gasolinas y Diésel (FC). La fórmula sería:

$F G I I P=(I V F G D+F C) * 0.20$

El $70 \%$ de la cantidad generada se asigna según la proporción de habitantes del municipio respecto al total del estado, el 30\% restante -el que corresponde al IVFGD- se distribuye en partes iguales a cada municipio, y el 30\% del FC se distribuye a los municipios que estén por debajo de la media estatal según criterio de pobreza extrema. 
iii. El Fondo Estatal para la Infraestructura de los Servicios Públicos Municipales -por su parte- se compone del 5\% de lo que le corresponda a la entidad en el Fondo General de Participaciones. Se distribuye en función de la recaudación del impuesto predial por municipio en los dos últimos ejercicios.

Las aportaciones federales, son recursos que ya tienen un fin predeterminado (recursos condicionados). Se ejercen en municipios a través de diversos fondos establecidos (véase cuadro 1). El FAISM corresponde al $2.197 \%$ de la recaudación federal participable y sigue un criterio compensatorio, mientras que el FORTAMUN se creó para apoyar las finanzas municipales y depende de la proporción de habitantes respecto del total estatal. Dentro de las aportaciones federales, estos dos fondos son los únicos que ejercen directamente los municipios.

\subsection{Egresos municipales.}

Los gobiernos locales de Michoacán para administrar su Hacienda presentan -primero- la propuesta de iniciativa de Ley de Ingresos Municipales ante el Congreso Local para su revisión y aprobación, el contenido de esta ley es elaborado inicialmente por el Tesorero y examinado por el Ayuntamiento. La vinculación de la Ley de Ingresos Municipales con los objetivos, las estrategias y las prioridades del Plan Municipal de Desarrollo debe ser clara. Luego, los gobiernos locales elaboran el Presupuesto Municipal de Egresos, para controlar y evaluar su gasto en función del Plan Municipal de Desarrollo. Este presupuesto es construido también por el Tesorero y aprobado por el Ayuntamiento, cuya aplicación es supervisada y fiscalizada por el Congreso Local. ${ }^{4}$ En este documento se analiza la relación entre ingresos y egresos. La Ley de Ingresos Municipal y el Presupuesto Municipal de Egresos corresponden a la actividad presupuestaria del gobierno local.

La función financiera del gobierno municipal se pone en marcha con la operación del presupuesto, que incluyen entre otras actividades la recaudación de ingresos, el ejercicio del gasto, la contabilización de los recursos utilizados y la presentación de la situación financiera ante las autoridades competentes y la ciudadanía en general.

El ejercicio del gasto puede ser por concepto corriente (costos administrativos recurrentes, son gastos que no producen resultados más allá de lo inmediato); de capital (cuando se utiliza para adquirir, mantener y/o mejorar bienes inmuebles o infraestructura física, pretenden incidir

\footnotetext{
${ }^{4}$ El Presupuesto Municipal de Egresos se elabora conforme a lo establecido en la Ley Estatal de Presupuesto, Contabilidad y Gasto Público.
} 
positivamente a largo plazo) ${ }^{5}$; servicios, transferencias y ayudas, y de deuda (pagar los compromisos financieros) (véase cuadro 2).

Cuadro 2

\section{Rubros del gasto municipal}

\begin{tabular}{|l|l|}
\hline \multirow{4}{*}{ 1. Gasto corriente } & Servicios personales. \\
\cline { 2 - 2 } & Materiales y suministros. \\
\cline { 2 - 2 } & Servicios generales. \\
\hline \multirow{2}{*}{$\begin{array}{l}\text { 2. Transferencias y } \\
\text { subsidios }\end{array}$} & Servicios, transferencias y ayudas. \\
\hline \multirow{3}{*}{ 3. Gasto de capital } & Bienes muebles, inmuebles e intangibles. \\
\cline { 2 - 2 } & Inversión pública. \\
\cline { 2 - 2 } & Inversiones financieras y otras provisiones. \\
\hline 4. Deuda & Deuda pública. Amortizaciones e intereses. \\
\hline
\end{tabular}

Fuente: elaboración propia con base en la Ley Estatal de Presupuesto, Contabilidad y Gasto Público.

El gasto corriente se compone de servicios personales (nómina), materiales y suministros (toda clase de materiales necesarios para la operación ordinaria), y servicios generales (toda clase de servicios requeridos para realizar las actividades ordinarias). No se incluyen los gastos por servicios, transferencias y ayudas debido a que no forman parte de los gastos de operación de los municipios, ni tienen efectos sobre el aparato administrativo de los mismos.

\section{Gasto corriente y efecto valor origen en las zonas rurales de Michoacán.}

\subsection{Los municipios rurales de Michoacán.}

Los municipios rurales de Michoacán (véase cuadro 3) se caracterizan por tener cabeceras municipales menores de 20,000 habitantes, la mayoría de su población habita en localidades de menos de 2,500 habitantes y bastante dispersas. Lógicamente, su densidad es más baja que el promedio estatal. Un importante porcentaje de las viviendas particulares cuenta con energía eléctrica. La cobertura en drenaje y agua de la red pública es baja. El nivel educativo es muy bajo, más que la

\footnotetext{
${ }^{5}$ La inversión del gobierno municipal reúne varias características: no son bienes destinados al consumo, tienen una duración previsiblemente superior al ejercicio presupuestal, son susceptibles de inclusión en inventario, y son erogaciones previsiblemente no reiterativas.
} 
media estatal (de por sí bajo). La Población Económicamente Ocupada (PEO) se concentra en actividades primarias y en poca medida en el sector terciario. La mayoría de sus gobiernos reciben ingresos brutos anuales menores a $\$ 40,000,000.00$ (Herrera, 2011: 104).

El escaso nivel de desarrollo económico alcanzado en estos municipios no genera las oportunidades de empleo necesarias, por lo que se tiende a migrar hacia las ciudades con la esperanza de encontrar mejores condiciones de vida, así como hacia Estados Unidos de Norteamérica, dejando en muchos casos poblaciones integradas casi por mujeres y niños. Todo esto ha sido caldo de cultivo para la propagación del crimen organizado.

En este contexto, los gobiernos de los municipios rurales, deben atender problemas administrativos, financieros y políticos a su interior, junto con la falta de ingresos de su población. Si a esto se agrega la lucha por el electorado, se entiende por qué no tienen las condiciones para elevar su recaudación por vías como el predial. Además, la inseguridad que permea al estado de Michoacán, y particularmente algunas zonas rurales de tierra caliente, de la costa y de la Ciénega de Chapala, conlleva grandes costos de oportunidad, pues se minan las bases tributarias al alejarse la inversión.

Cuadro 3

\section{Municipios Rurales de Michoacán}

\begin{tabular}{|l|l|l|l|}
\hline Acuitzio & Coeneo & La Huacana & Tiquicheo \\
\hline Aguililla & Contepec & Lagunillas & Tlalpujahua \\
\hline Angamacutiro & Copándaro & Madero & Tlazazalca \\
\hline Angangueo & Ecuandureo & Morelos & Tocumbo \\
\hline Aporo & Epitacio Huerta & Nocupétaro & Tumbiscatío \\
\hline Aquila & Erongarícuaro & Nuevo Urecho & Turicato \\
\hline Ario & Gabriel Zamora & Ocampo & Tuxpan \\
\hline Arteaga & Huaniqueo & Panindícuaro & Tuzantla \\
\hline Carácuaro & Huetamo & Penjamillo & Tzintzuntzan \\
\hline Carácuaro & Huiramba & Salvador Escalante & Tzitzio \\
\hline Chinicuila & Ixtlán & San Lucas & Villamar \\
\hline Chucándiro & Jiménez & Senguio & Zináparo \\
\hline Churintzio & José Sixto Verduzco & Susupuato & Zinapécuaro \\
\hline Churumuco & Juárez & Tancítaro & Ziracuaretiro \\
\hline Coalcomán & Jungapeo & & \\
\hline
\end{tabular}

Fuente: Herrera, 2011: 101-102. 


\subsection{Comportamiento de los egresos de los municipios rurales de Michoacán, 2001 - 2015. ${ }^{6}$}

El gasto corriente en los municipios rurales alcanza en promedio un $48 \%$ respecto al gasto total (véase gráfica 1), llegando al máximo en el municipio de Tocumbo con 64\%, mientras que es el municipio de Ocampo el que tiene el menor porcentaje (35\%). Estos porcentajes son ligeramente menores que los obtenidos por los municipios semi-urbanos.

\section{Gráfica 1}

\section{Relación Gasto Corriente / Gasto total (sólo municipios en los extremos)}

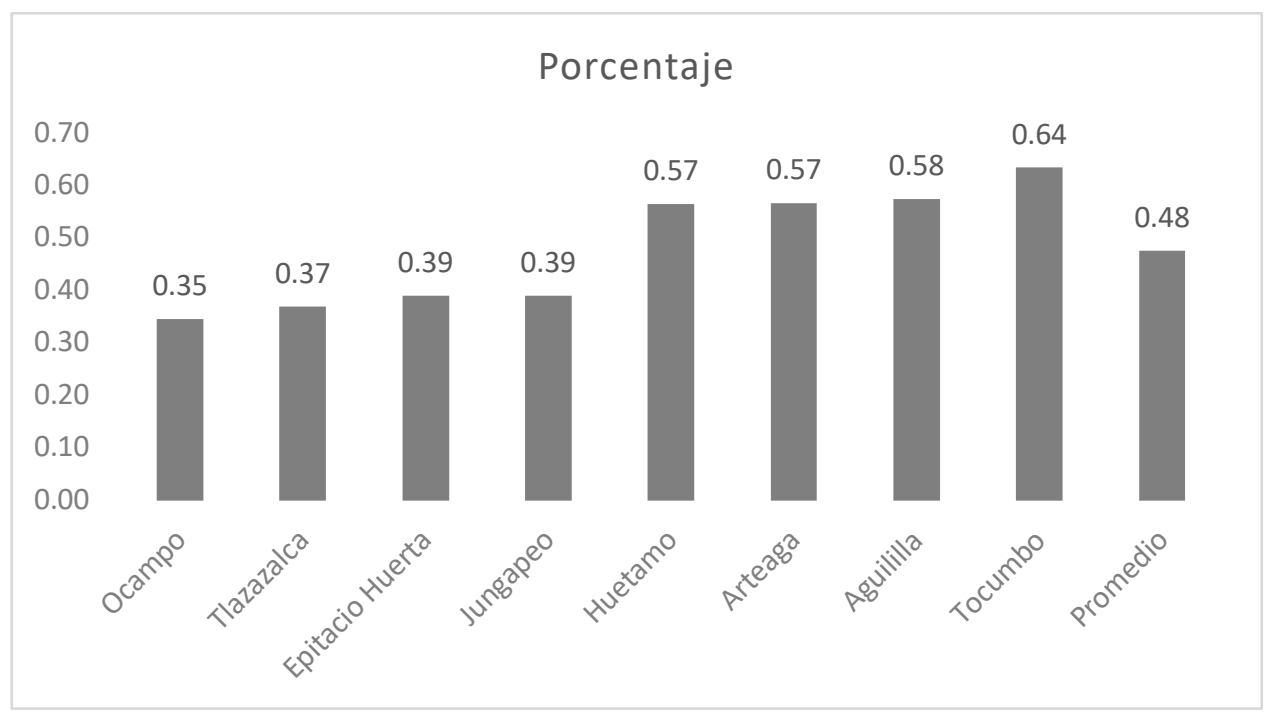

Fuente: elaboración propia.

Comparando el gasto corriente respecto a los Ingresos de Libre Aplicación (ILA), esto es, ingresos propios más participaciones, se encuentra que el promedio es de $105 \%$, indicando que los ILA no alcanzan a cubrir el gasto corriente. El valor mínimo lo presenta Aporo con $70 \%$, y el máximo Huetamo con 131\%. En los municipios rurales hay más dispersión en los resultados que en los semiurbanos (véase gráfica 2).

\footnotetext{
${ }^{6}$ Los datos para el diagnóstico de los egresos se obtuvieron del INEGI y se usaron a precios constantes.
} 


\section{Relación gasto corriente / Ingresos de libre aplicación}

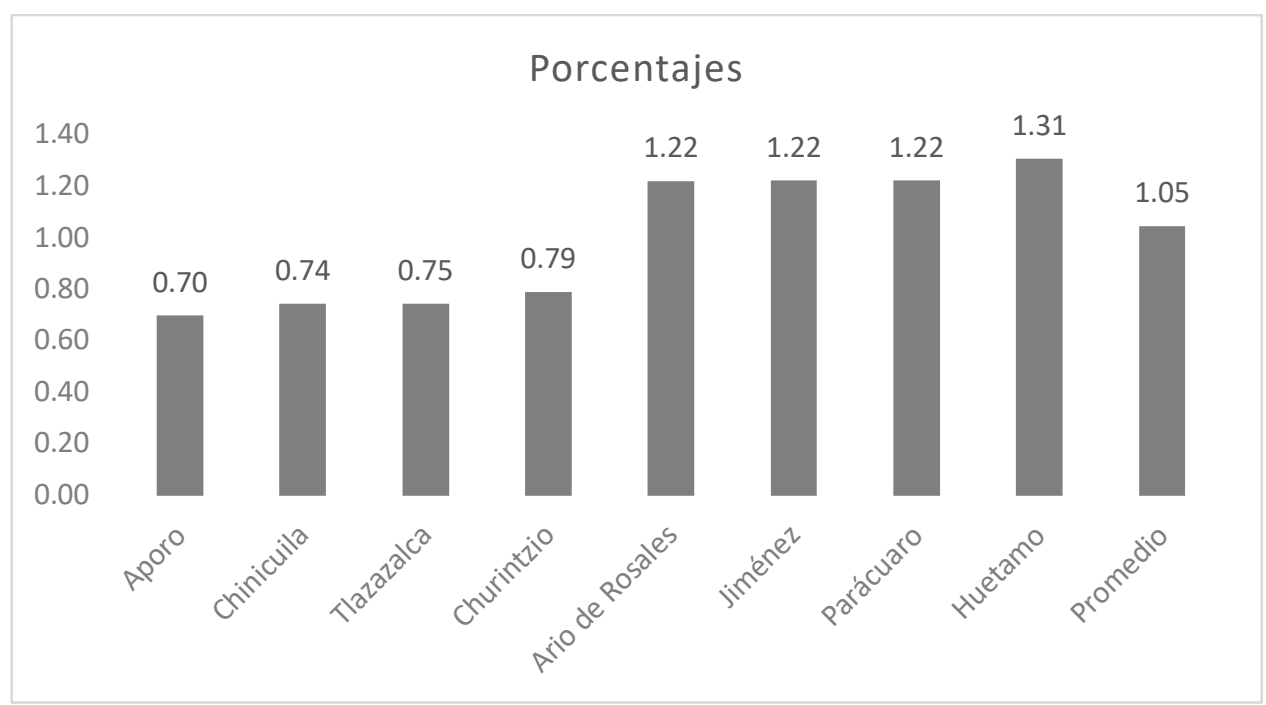

Fuente: elaboración propia.

Otro aspecto importante es el referido a la proporción de ingresos propios sobre los ingresos totales (gráfica 3). Ésta indica en qué medida los municipios pueden contar con autonomía financiera y por tanto depender menos de los recursos vía transferencias. La proporción cambia entre el 2 y el $18 \%$, correspondiendo el $18 \%$ a Tocumbo y el $2 \%$ a Tiquicheo, siendo de $8 \%$ la media. En promedio se recauda menos de fuentes propias que en los municipios semi-urbanos y urbanos. También se observa que son los municipios -como tendencia- más marginados los que menos recaudan. 


\section{Ingresos propios / Ingresos totales}

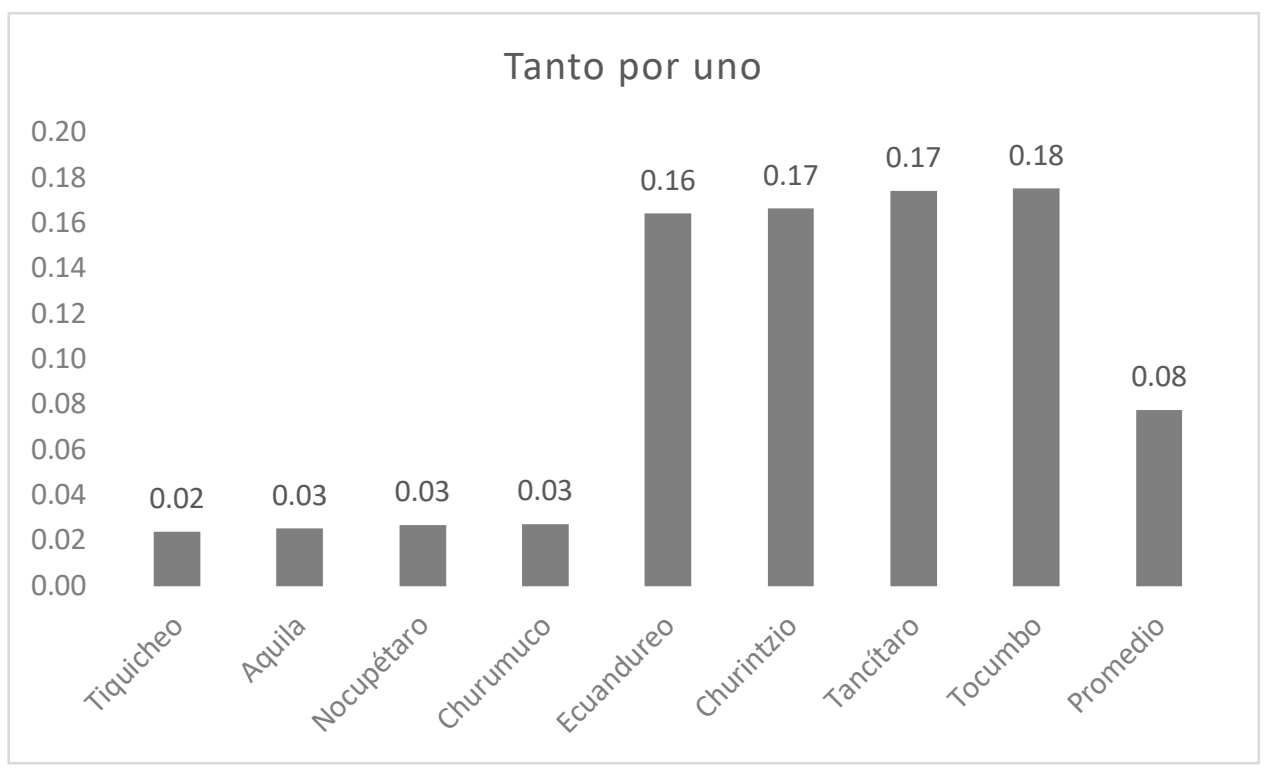

Fuente: elaboración propia.

Del análisis de los resultados se encuentra que:

i. La relación del gasto corriente con respecto a los egresos totales no alcanza el $50 \%$ en promedio, con casos críticos que superan el $60 \%$. Si bien es alta, es menor que en los municipios poblacionalmente más grandes.

ii. Los ingresos de libre aplicación (ILA), no son suficientes para cubrir el monto de gasto corriente en la mayor parte de los municipios rurales, por tanto, no alcanzarán para generar acciones locales que potencien al desarrollo municipal a través de inversión, por lo que los municipios rurales estarán condenados al municipio al subdesarrollo.

iii. En promedio los ingresos propios representan poco menos del 8\%, ni una doceava parte de los recursos necesarios. Esta situación no es nueva en México, pero sí muy grave, significando una autonomía financiera prácticamente inexistente -más notable en los municipios rurales que en los no rurales-, y por tanto una dependencia considerable hacia las transferencias federales, participaciones federales y aportaciones federales-estatales (Ramo 28 y 33, respectivamente).

Esto muestra que la descentralización que se ha llevado a cabo, está caracterizada por la falta de articulación/congruencia, sin obedecer a un plan bien definido, debiéndose más a razones casuales e inmediatas. Se han descentralizado obligaciones, pero no potestades tributarias en la misma medida, 
son más las obligaciones que se tienen que las capacidades para recaudar recursos, especialmente de fuentes propias. Ello redunda en profundización de las desigualdades, tanto vertical como horizontal.

Afortunadamente, la gran dependencia que presentan los municipios rurales respecto de las transferencias federales, que en teoría podría propiciar endeudamiento sub-nacional, aún no se manifiesta en los municipios rurales de Michoacán. Si bien algunos pocos municipios tienen deuda, ésta se ubica en niveles relativamente bajos. ${ }^{7}$

\subsection{Cálculo del efecto valor de origen.}

Para el cálculo del efecto valor origen se requiere medir la sensibilidad que el gasto corriente tiene con respecto a los ingresos propios y a las participaciones federales. Es conveniente subrayar que el gasto corriente debe solventarse con ingresos propios y participaciones federales, no se puede liquidar con otros recursos, pues ya están condicionados (aportaciones federales y estatales) ${ }^{8}$ o deben ser para gasto productivo (financiamiento).

Como primera herramienta para la estimación del grado de elasticidad del gasto corriente, se usará un modelo con datos de panel, con logaritmos. Al usar logaritmos los resultados presentan directamente la elasticidad de las variables en cuestión (Gujarati, 2010: 160). El método a utilizar es el de mínimos cuadrados robustos para datos de panel, para minimizar el efecto de los datos atípicos. El modelo a estimar es (los resultados se muestran en el cuadro 4):

$$
\log G \operatorname{corr}=\beta_{1}+\beta_{2} \log I p+\beta_{3} \log P a r t+\beta_{4} \operatorname{Sim}+u i
$$

Donde:

Gcorr $=$ Gasto corriente.

Ip $=$ Ingresos propios.

Part $=$ Participaciones.

Sim $=$ Coeficiente de asimetría.

$\log =$ Logaritmo.

$U i=$ Término de error.

\footnotetext{
${ }^{7}$ Los municipios más endeudados, para el caso de Michoacán, son los urbanos y muy urbanos, principalmente Morelia y Uruapan.

${ }^{8}$ En teoría, tampoco es posible usar recursos vía endeudamiento para este fin, por las disposiciones legales al respecto.
} 
Cuadro 4

\section{Resultados de la regresión}

\begin{tabular}{|c|c|c|c|c|c|}
\hline & $\beta_{1}$ & $\beta_{2} \log I p$ & $\beta_{3} \operatorname{LogPart}$ & $\beta_{4} \mathrm{Sim}$ & $R^{2}$ ajustada \\
\hline Parámetros & 0.644102 & 0.098544 & 0.901504 & +0.007800 & 0.777367 \\
\hline Error Std & 0.054208 & 0.008344 & 0.008649 & 0.012863 & \\
\hline Valor-P & 0.0000 & 0.0000 & 0.0000 & 0.5442 & \\
\hline
\end{tabular}

Fuente: elaboración propia.

Claramente es mayor la respuesta del gasto corriente ante cambios en las participaciones $(90.15 \%)$ que debida a modificaciones en los ingresos propios $(9.85 \%)$, lo que muestra la ineficiencia de financiar el gasto corriente con ingresos vía participaciones. El coeficiente de simetría, que muestra que el gasto corriente no varía en la misma proporción que las transferencias cuando éstas disminuyen, sale no significativo, lo que indica que no puede asegurarse que sea de una u otra manera para el caso de los municipios rurales de Michoacán en el período analizado.

Complementando y para obtener los resultados por municipio, su usará la manera sugerida por López (2004: 30). Este método la fórmula:

$$
V O g c=\frac{\boldsymbol{e} g c / p}{\boldsymbol{e} g c / i p}
$$

Donde el numerador indica la elasticidad del gasto corriente respecto a las participaciones, y el denominador muestra la elasticidad de dicho gasto, pero en respuesta a los ingresos propios. Si el resultado es mayor a la unidad, el gasto corriente será más elástico a las participaciones. En caso contrarios el gasto corriente será más sensible a los ingresos propios.

\subsection{Análisis e interpretación de datos.}

De acuerdo con los resultados mostrados en el cuadro 5, el gasto corriente en los municipios rurales de Michoacán, es mucho más sensible a las participaciones que a los ingresos propios durante el período de análisis. 


\section{Cuadro 5}

\section{Valor de Origen}

Resultados globales

\begin{tabular}{ll}
\hline Promedio & 5.80235109 \\
\hline Máximo & 121.986149 \\
\hline Mínimo & 0 \\
\hline
\end{tabular}

Fuente: elaboración propia.

Sin embargo y como es normal, algunos municipios presentan un valor de origen bajo (cuadro 6). Así, los municipios con menor valor de origen son Morelos. Jiménez y Penjamillo. Esto se muestra en el siguiente cuadro:

\section{Cuadro 6}

\section{Municipios con menor}

Valor de origen

\begin{tabular}{lr}
\hline Lagunillas & $\mathbf{- 5 . 8 6 5 2 4 2 5 6}$ \\
\hline Aporo & -6.1386272 \\
\hline Tlazazalca & -6.74224163 \\
\hline Epitacio Huerta & -7.45441261 \\
\hline Carácuaro & -9.2871887 \\
\hline Jungapeo & -12.8850343 \\
\hline Madero & -14.3641668 \\
\hline Penjamillo & -15.8359262 \\
\hline Jiménez & -92.1264184 \\
\hline Morelos & -125.325089 \\
\hline
\end{tabular}

Fuente: elaboración propia.

Del otro lado, los municipios que han presentado un alto valor de origen se presentan en el cuadro 7, donde se puede ver que Ixtlán, Erongarícuaro y Chinicuila tienen los más altos valores. 
Cuadro 7

\section{Municipios con mayor}

Valor de origen

\begin{tabular}{lr}
\hline Ixtlán & 121.986149 \\
\hline Erongarícuaro & 81.1932753 \\
\hline Chinicuila & 65.2790615 \\
\hline Copándaro & 37.2367958 \\
\hline Coeneo & 31.4781233 \\
\hline Huiramba & 28.998548 \\
\hline Angamacutiro & 25.5892735 \\
\hline San Lucas & 24.5626931 \\
\hline Juárez & 21.7284261 \\
\hline Nuevo Urecho & 20.4889786 \\
\hline
\end{tabular}

Fuente: elaboración propia.

En más de la mitad de los municipios rurales de Michoacán hubo más grado de sensibilidad en el gasto corriente cuando éste se pagó con participaciones federales, este resultado indica que, si se pretende lograr mejores resultados, el gasto local deberá ser financiado con recursos provenientes de fuentes propias.

Por ello, es prioritario diseñar estrategias tendientes a incrementar los ingresos propios. A largo plazo deberán llevarse a cabo modificaciones a la Ley Nacional de coordinación Fiscal, que actualmente centraliza los impuestos que son relevantes, dejando para los municipios sólo aquellos que recaudan ingresos marginales. Modificaciones a dicha Ley permitirían financiar en buena medida el gasto corriente con ingresos propios, reduciendo el uso ineficiente del gasto corriente. Los resultados empíricos muestran que el gasto corriente es menos sensible cuando se financia con recursos de fuentes propias. Por lo pronto, habrá que usar mejor las potestades tributarias que ya se tienen, aunque es preciso manifestar que, para el caso de los municipios rurales, caracterizados por la pobreza y la marginación -en su mayoría-, esto no cambiará mucho las cosas.

La propuesta de López (2004: 44-45), de reglamentar el porcentaje que debe cubrirse de gasto corriente con ingresos propios, no es pertinente para los municipios rurales de Michoacán, por el nivel de pobreza y marginación que les caracteriza. 


\section{$\Rightarrow$ 5. Conclusiones.}

Los municipios rurales de Michoacán presentan un incremento muy grande del gasto corriente si es cubierto con recursos recibidos vía transferencias. Por su parte, sus ingresos propios no llegan en promedio al $8 \%$, lo que muestra por un lado la alta dependencia respecto de los recursos federales y, por otro, su baja autonomía financiera (Tiquicheo, uno de los municipios rurales, sólo recauda de fuentes propias el $2.4 \%$ de sus ingresos totales).

La relación del gasto corriente respecto a los egresos totales es mucho mayor que la relación ingresos propios-ingresos totales, $47.7 \%$ y $7.8 \%$, respectivamente. Desde el ángulo de los ingresos de libre aplicación (participaciones federales e ingresos propios), la totalidad, como monto, son usados para cubrir el gasto corriente (los ingresos de libre aplicación llegan al 46.6 del total, en tanto que el gasto corriente es el $47.7 \%$ ), en los casos donde sobran pequeños montos se orientan para ayudas sociales y subsidios.

El gasto de inversión es relativamente bajo, y aun así no alcanza a ser financiado con recursos propios. De acuerdo con esto, los municipios rurales de Michoacán dependen de fuentes de recursos que no están bajo su control para sentar bases para el desarrollo.

Para mejorar su situación financiera, el camino está en aumentar los ingresos propios, lo cual se puede atender en el corto plazo mejorando la eficiencia en la recaudación de las fuentes que la ley les confiere (principalmente el predial), pero a largo plazo la solución está en modificar la Ley Nacional de Coordinación Fiscal y el Sistema Nacional de Coordinación Fiscal, de modo tal que se incrementen las potestades tributarias que hoy tienen. Esto es necesario porque el sistema federal de nuestro país les ha conferido obligaciones que no han sido compensadas con las correspondientes potestades tributarias. 


\section{Bibliografía y referencias documentales}

Courant, P.; Gramlich, H. y Rubinfeld, D. (1979). The Stimulative Effects of Intergovernmental Grants: or Why Money Sticks Where It Hits, en P. Mieszkowski, P. y Oakland, W. (eds.), Fiscal Federalism and Grants-In-Aid, 5-21.

Gujarati, Damodar y Porter, Dawn (2010), Econometria, 5a Edición, Mc Graw Hill, México.

Herrera, Hugo (2011), Evaluación del desempeño municipal. Propuesta metodológica para los municipios rurales del Estado de Michoacán, México: Instituto Nacional de Administración Pública, A.C.

Hines, J. y Thaler, R. (1995). Anomalies: The Flypaper Effect. Journal of Economic Perspectives. IX (4), $217-$ 22.

INAFED (s/f), Información básica sobre administración y gobierno municipal, México: Secretaría de Gobernación.

Inman R.P. (2009) Flypaper Effect. In: Palgrave Macmillan (eds) The New Palgrave Dictionary of Economics. Palgrave Macmillan, London.

Kalb, A. (2010). The Impact of Intergovernmental Grants on Cost Efficiency: Theory and Evidence from German Municipalities, Economic Analysis and Policy, XL (1), 23-48.

Ley de Coordinación Fiscal del Estado de Michoacán de Ocampo (2008), última reforma: 05 de diciembre de 201. Disponible en:

Ley de Hacienda Municipal del Estado de Michoacán de Ocampo (2014). Disponible en: http://transparencia.congresomich.gob.mx/media/documentos/trabajo legislativo/LEY DE HACIE NDA MUNICIPAL DEL ESTADO 25 DE DICIEMBRE DE 2014.pdf

Ley de Ingresos Municipales del Estado de Michoacán de Ocampo (2020). Disponible en: http://transparencia.congresomich.gob.mx/media/documentos/trabajo_legislativo/ley_de_ingresos_pa ra los municipios.pdf

Ley Nacional de Coordinación Fiscal (1978), última reforma: 20 de enero de 2018. Disponible en: http://www.diputados.gob.mx/LeyesBiblio/pdf/31_180716.pdf

Ley de Presupuesto, Contabilidad y Gasto Público del Estado de Michoacán de Ocampo (2003), última reforma: 21 de noviembre de 2007.2 Disponible en: http://docs.mexico.justia.com.s3.amazonaws.com/estatales/michoacan/ley-de-presupuestocontabilidad-y-gasto-publico-del-estado-de-michoacan-de-ocampo.pdf

López, Mauricio (2004), Finanzas municipales en México: en la búsqueda de un eficiente comportamiento de los egresos, Documento de trabajo No. 147, México: CIDE, A.C.

Sour, L. (2013). The flypaper effect in Mexican local governments. Estudios Económicos, XXVIII (1), 165186.

Stiglitz, Joseph (1988). La economía del sector público, Segunda edición, Barcelona: Antoni Bosch. 


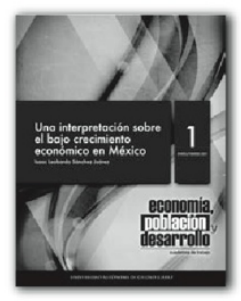

Economia, población y desarrollo.
Cuadernos de trabajo №1 Enero-Febrero 2011
Una interpretación sobre el bajo

recimiento económico en México
Isaac Leobardo Sánchez Juárez
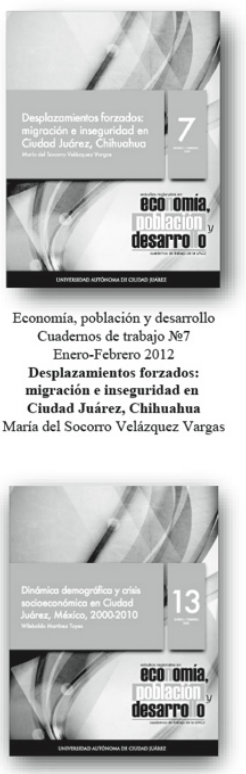

Economia, población y desarroll
Cuarednos de trabajo No 13 Enero - Febrero 2013

Dinámica demografica y crisis México, 2000-2010
Wilcbaldo Martinez Toyes
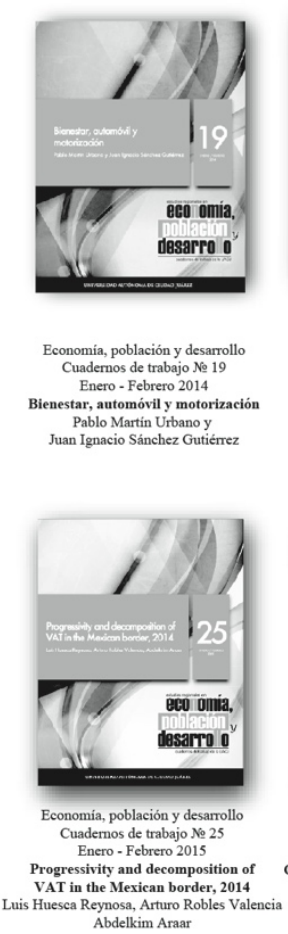
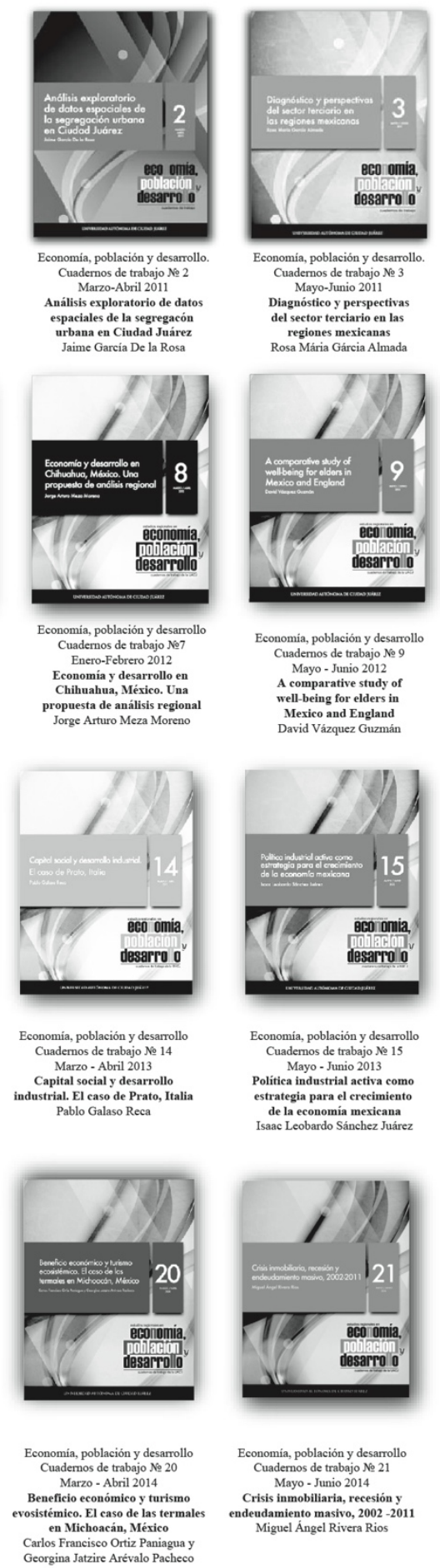

Economía, población y desarrollo
Cuadernos de trabajo № 2 Marzo-Abril 2011 espaciales de la segregacón Jaime Garcia De la Rosa

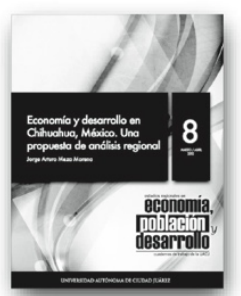

Economia, poblacíón y desarrollo
Cuadernos de trabajo Ne7 Cuadernos de trabajo No7
Enero-Febrero 2012 Economía y desarrollo en
Chihuahua, México. Una propuesta de análisis regional
Jorge Arturo Meza Moreno

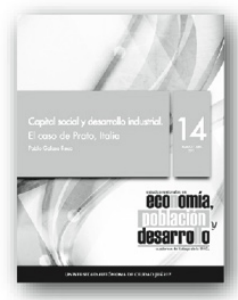

Economia, población y desarrollo Cuademos de trabajo $\mathrm{N}$.
Marzo - Abril 2013 Capital social y desarrollo
industrial. El caso de Prato, Italli Pablo Galaso Rec
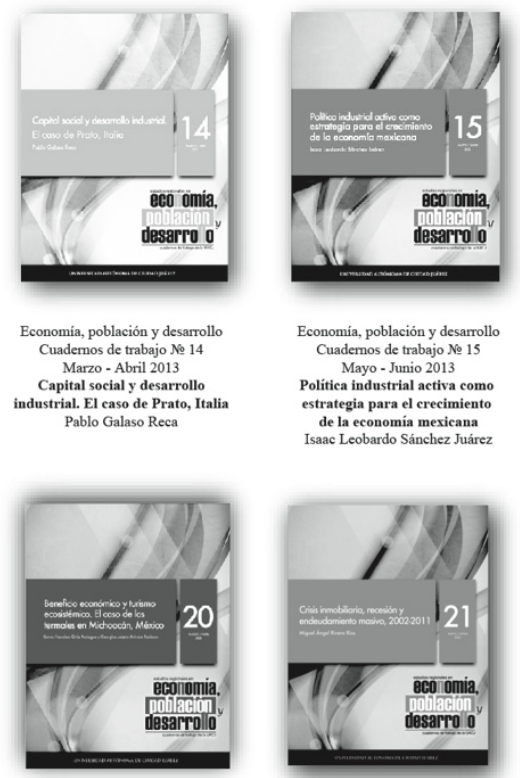

Economia, población y desarrollo Mayo - Junio 2013 Politica industrial activa como estrategia para el crecimiento
de la economia mexicana

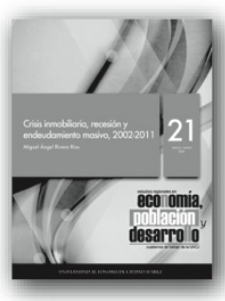

conomia, población y desarrollo Maadernos de trabajo $\mathrm{N}$ - Junio 2014
Mats Crisis inmobiliaria, recesión y
ndeudamiento masivo, $2002-2011$ deudamiento masivo, 2002 - 20
Miguel Ángel Rivera Rios
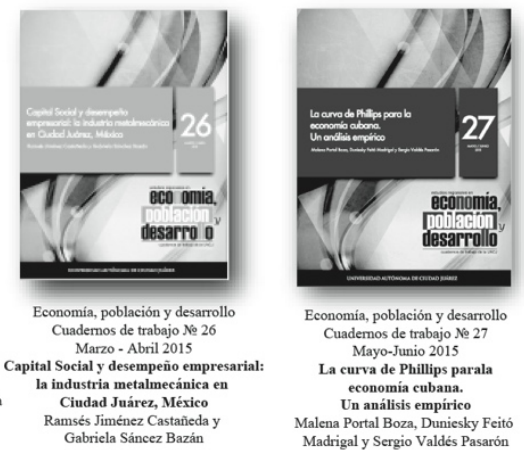

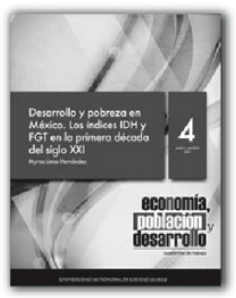

Economia, población y desarrollo Cuademos de trabajo $\mathrm{N}$
julio-Agosto 2011

Dasarrollo y pobreza en México. Los indices IDH y FGT en la
primera década del siglo XXX

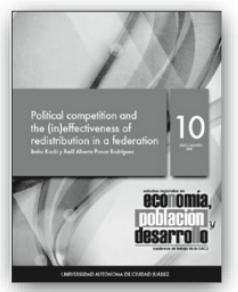

Economia, población y desarrollo Julio - Agrosto 2012

Polititical competition and

(ii)effectiveness of

Ikuho Kochi y Raúl Alberto Ponce
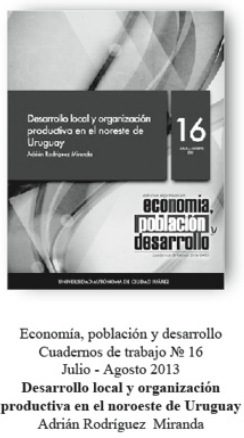
Sarah Bemal Salazar
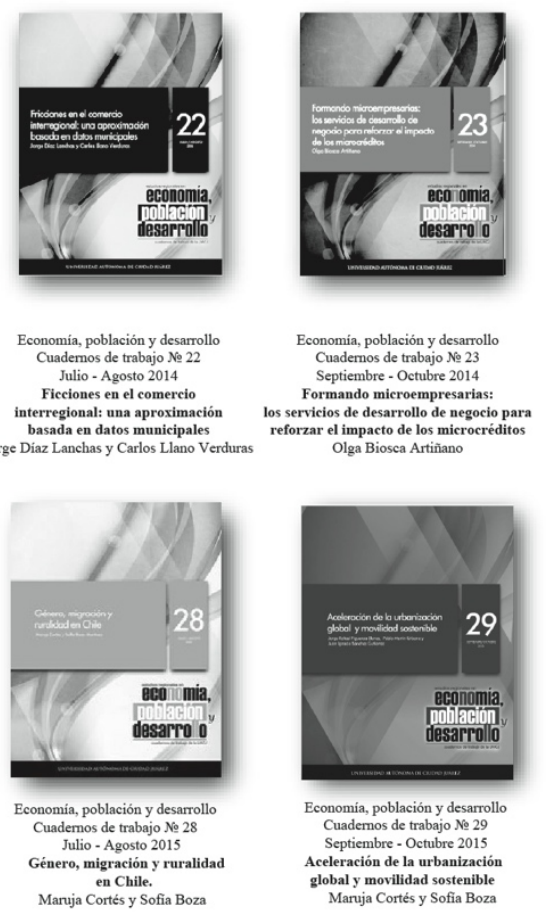

Suademos de trabajo
Las transe-Octubre e 011
Lasferencias

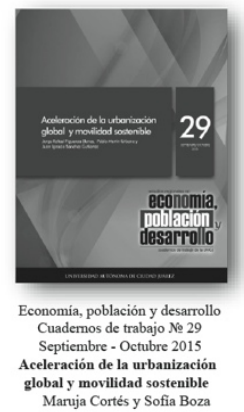
Olga Biosca Artiñan
Cuadernos de trabajo № 17 Septiembre - Octubre 2013
Vulnerabilidad social y vivienda en Sonora, México

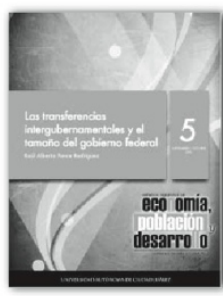

Economia, población y desarrollo
Cuademos de trabajo No5 $^{0}$

intergubernamentales $y$ el
tamaño del gobierno federal

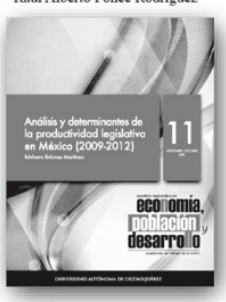

Economia, población y desarroll Septiembre - Octubre 2012

a productividad legislativa en México (2009-2012)
Bárbara Briones Martinez
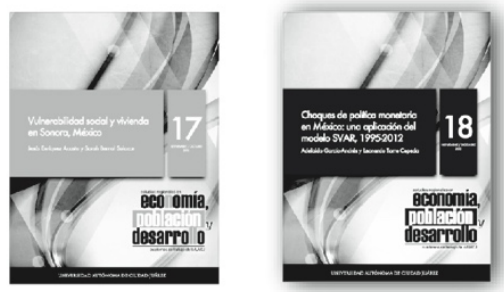

Economia, población y desarroll Noviembre - Diciembre 2013 Choques de politica monetaria modelo SVAR, 1995-2012

Cuademos de trabajo № 12 Noviembre - Diciembre 2012
gricultura organica y desarroll $n$ análisis comparativo entre Sofia Boza Martinez

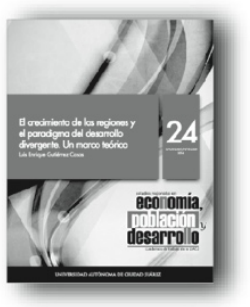

Cuademos de trabajo No $_{2} 24$ Noviembre - Diciembre 2014 el paradigma del las regiones divergente. Un marco teórico

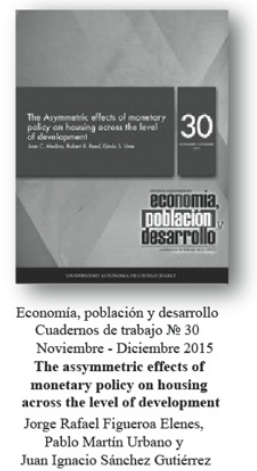



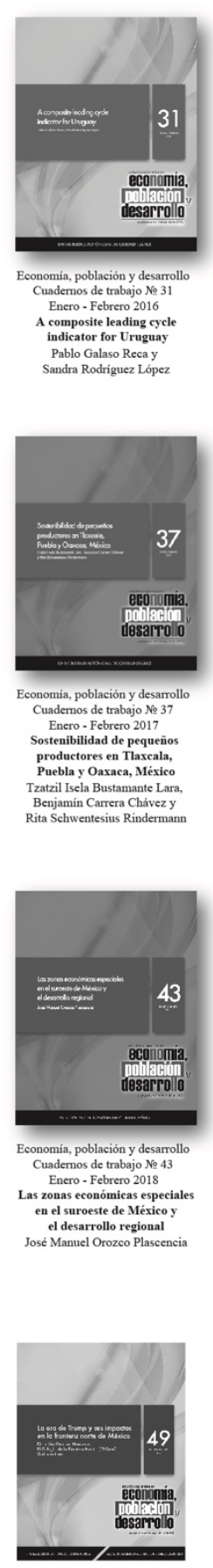

Economia, población y desarrollo Cuadernos de trabajo No 49
Enero - Febrero 2019 Enero - Febrero 2019
La era de Trump y sus impactos Varios autores

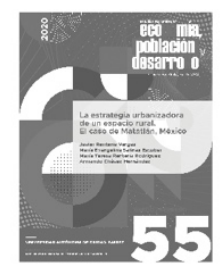

Economia, población y desarrollo Cuademos de trabajo №
Enero - Febrero 2020 La estrategia urbanizadora de un espacio rural.
El caso de Matatlann, México. Javier Renteria Vargas, Maria Evangelina Salinas Escobar, Maria Evangelina Salinas Escobar,
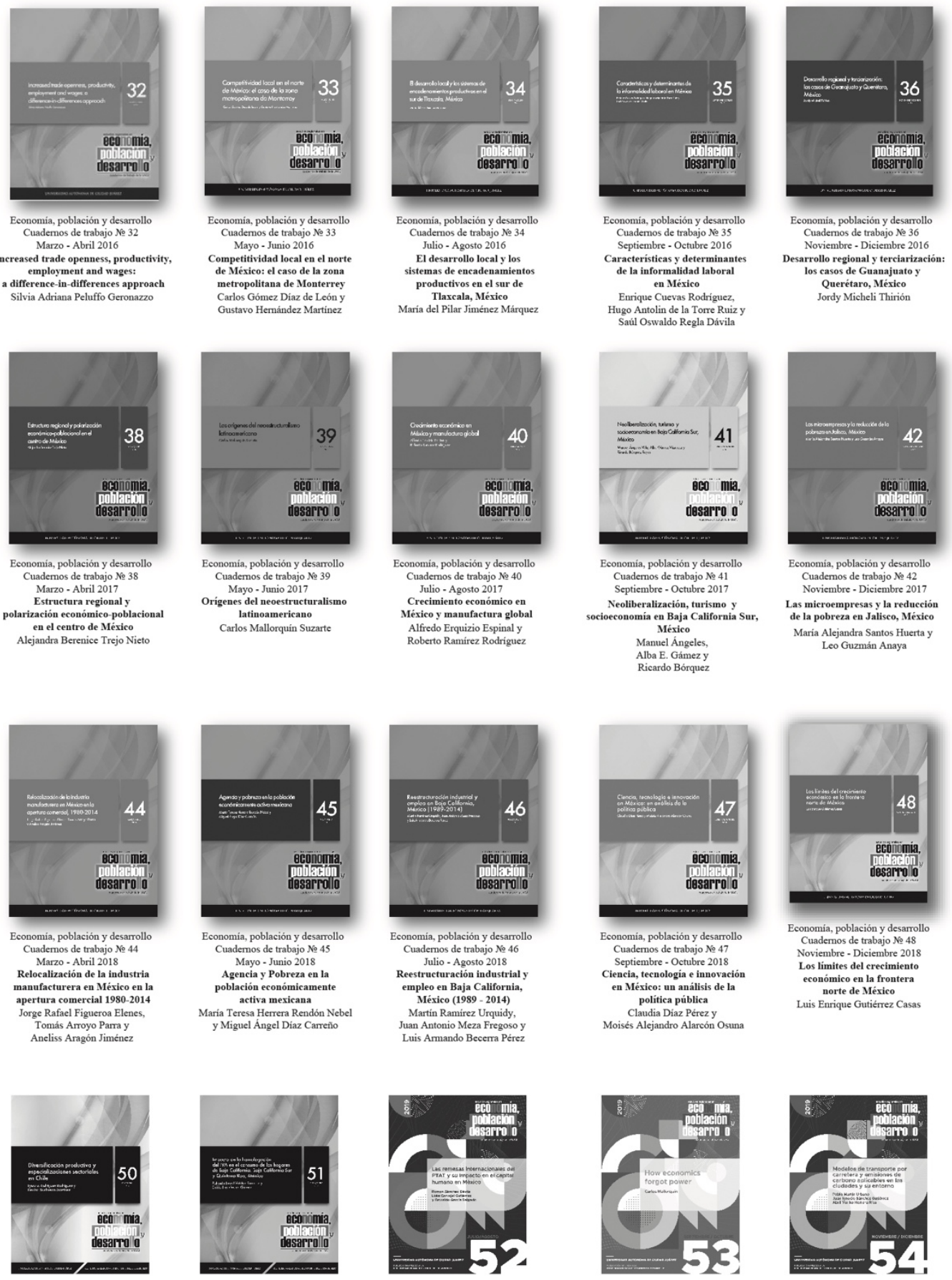

Economia, población y desarrollo
Cuadernos de trabajo № 50 Marzo - Abril 2019 Diversificación productiva y
especializaciones sectoriales en $\mathrm{CH}$ Ignacio Rodriguez Rodrigucz
Paulina Sanhueza Martinez

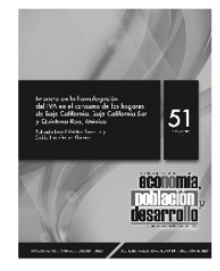

Economia, población y desarrollo
Cuadernos de trabajo № 51 Mayo - Junio 2019
Impacto de la homologación del IVA Impacto de la homologación del IVA
en el consumo de los hogares de
Baja Califoria, Baja Baja Califoria, Baja Califforia Ser
Quintana Roo, Mérico Rolando Israel Valdez Ramirez y
Emilio Hernández Gómez
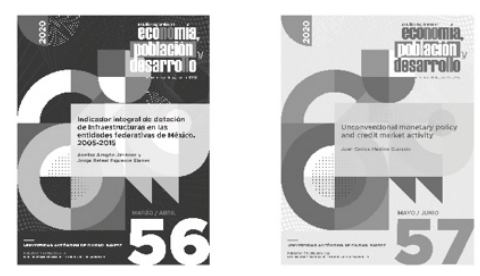

$$
\begin{aligned}
& \text { Economia, población y desarrollo } \\
& \text { Cuademos de trabajo No } 56 \\
& \text { Marzo - Abrir } 2020 \\
& \text { Indicador integral de dotación de } \\
& \text { infraestructuras en las entidades } \\
& \text { federativas de México, } \\
& \text { 2005-2015 } \\
& \text { Aneliss Aragón Jiménez y } \\
& \text { Jorge Rafael Figueroa Elenes }
\end{aligned}
$$

Economia, población y desarrollo
Cuadernos de trabaje No 57 Mayo - Junio 2020 Unconventional monetary policy
and creditmarket activity Juan Carlos Medina Guirado

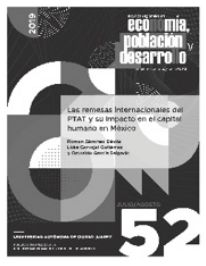

Economia, población y desarrollo
Cuademos de trabajo № 52 Cuadernos de trabajo No
Julio - Agosto 2019 Las remesas internacionales
del PTAT y su impacto en el capital humano Román Sánchez Dávila
Lidia Carvajal Gutiérrez

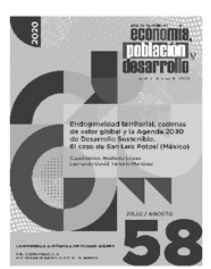

Economia, población y desarrollo Cuadernos de trabajo 20
Julio - Agosto 2020 Endogeneidad territorial, cadenas de valor global y la
Agenda 2030 de Desarrollo Sostenible. Agenda 2030 de Desarrollo Sostenible.
El caso de San Luis Potosi (México) Cuauhtémoc Modesto López y
Leonardo David Tenorio Martinez

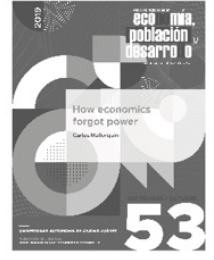

Economia, población y desarrollo Cuademos de trabajo № 53
Septiembre - Octubre 2019 How economics Carlos Mallorquin
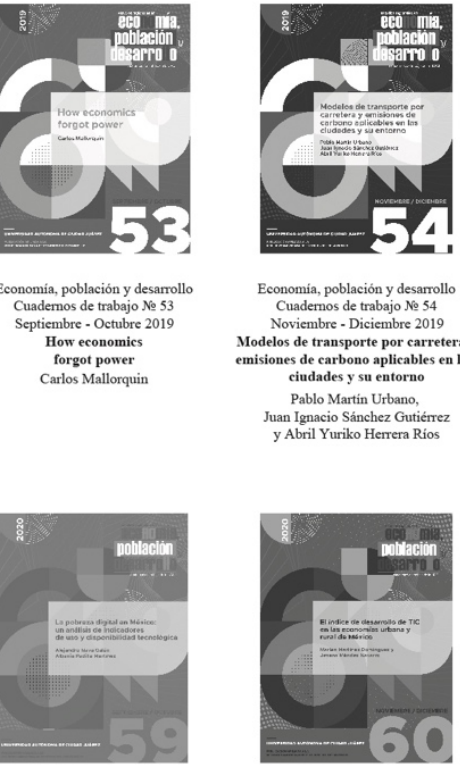

Economia, población y desarrollo Cuadernos de trabajo № 54
Noviembre - Diciembre 2019 Modelos de transporte por carretera $y$ misiones de carbono aplicables en Juan Ignacio Sánchez Gutiérrez
y Abril Yuriko Herrera Rios

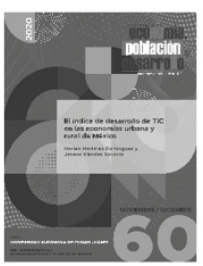

Economiá, población y desarrollo
Cuadermos de trabajio № 59 Septiembre - Octubre 2020 La pobreza digital en México:
un análisis de indicadores de uso an análisis de indicadores de uso $y$
disponibilidad tecnológica Alejandro Nava Galín y
Albania Padilla Martinez
Economia, población y desarollo dernos de trabajo № El indice de desarrollo de TIC en las economias
urbana y ruaral de Méxic Marlen Martinez Dominguez y 


\section{Para el documento general:}

Tipo de letra: Times New Roman.

Tamaño: 11 puntos.

Interlineado: 1.5 espacios.

Títulos y subtítulos:

El texto principal en 11 puntos. Títulos 12 puntos (en resaltado). Subtítulos 11 puntos. Cada título y subtítulo deberá numerarse bajo el siguiente orden: 1, 1.1, 2, 2.1, 2.2...

La extensión máxima de los cuadernos de trabajo será de 40 cuartillas.

La primera vez que se emplee una sigla en el texto se especificará primero su equivalencia completa y después la sigla.

\section{Hoja de presentación:}

Título:

14 puntos, centrado, resaltado.

Nombre de autor(es):

12 puntos

Resumen y abstract:

Debe incluir resumen en español y abstract (diez puntos), no mayor a 250 palabras

Palabras clave:

Incluir entre tres y cinco palabras clave, en español e inglés

Referencia del autor o autores:

Institución de adscripción, grado académico y líneas-grupos de investigación que desarrolla y a los que pertenece.

\section{Sistema de referencia de citas:}

Harvard-APA

Las citas bibliográficas en el texto deberán incluir entre paréntesis sólo el apellido del autor, la fecha de publicación y el número de página; por ejemplo: (Quilodrán, 2001: 33).

\section{Notación en sección de bibliografía y fuentes de información:}

Se deberá incluir al final del texto. Toda referencia deberá estar mencionada en el texto o notas de pie de página.

Cada referencia iniciará con el primer apellido o los apellidos, luego el nombre del autor, y después, entre paréntesis, el año de publicación seguido de un punto. Ejemplos:

Se deberá incluir al final del texto. Toda referencia deberá estar mencionada en el texto o notas de pie de página.

Cada referencia iniciará con el primer apellido o los apellidos, luego el nombre del autor, y después, entre paréntesis, el año de publicación seguido de un punto. Ejemplos: 
Artículo:

Ros, Jaime (2008). "La desaceleración del crecimiento económico en México desde 1982”, en Trimestre Económico, vol. 75, núm. 299, pp. 537-560.

Libro:

Villarreal, René (2005). Industrialización, competitividad y desequilibrio externo en México.

Un enfoque macroindustrial y financiero (1929-2010), México, Fondo de Cultura Económica.

Capítulo de libro:

Castillo, Manuel Ángel (2003). "La política de inmigración en México: un breve recuento", en Manuel Ángel Castillo, Alfredo Lattes y Jorge Santibáñez (coords.), Migración y fronteras, Tijuana,

El Colegio de la Frontera Norte / Asociación Latinoamericana de Sociología / El Colegio de México, pp. $425-451$.

\section{Notas de pie de página:}

Se utilizarán para hacer indicaciones complementarias, aclaraciones o ampliación de una explicación. La nota de pie de página en Times New Roman, 10 puntos.

\section{Tipología de imágenes dentro del texto:}

Cuadro

Gráfica

Diagrama

Mapa

Figura

Todas las imágenes deben ser numeradas y mencionadas dentro del texto. A toda imagen debe incluirse la fuente.

Las indicaciones de la imagen: tipo y número de imagen, título de imagen y fuente se escriben en 10 puntos. En el texto poner como imagen los mapas, figuras, gráficas y diagramas -con el ánimo de no perder el formato realizado por el autor.

\section{Ecuaciones y fórmulas:}

Si se utilizan ecuaciones o fórmulas deberá utilizarse el editor de ecuaciones de Word y numerarse.

\section{Envío de trabajos}

Los trabajos deben ser enviados a la dirección de correo: lgtz@uacj.mx. Con el Dr. Luis Enrique Gutiérrez Casas, editor de esta publicación.

La aceptación de cada colaboración dependerá de la evaluación de dos dictaminadores especialistas en la materia que se conservarán en el anonimato, al igual que el autor (autores) para efectos de la misma. 


\section{For General Document:}

Font type: Times New Roman.

Size: font size 11 .

Paragraph: 1.5 line spacing.

Titles and subtitles: Main text font size 11. Titles font size 12 (Bold). Subtitles font size 11.

Each title and subtitle should be numbered in the following order: 1, 1.1, 2, 2.1, 2.2...

The maximum length of the workbooks will be 40 pages.

The first time an abbreviation is used in the text will be specified first complete equivalence and then stands.

\section{Front cover:}

Title:

Font size 14, centered, Bold.

Author name(s):

Font size 12.

Abstract:

It should include abstract in Spanish and abstract (font size 10), no more than 250 words.

Keywords:

Include three to five keywords, in Spanish and English.

Reference of author:

Institution of affiliation, academic degree and line-developed by research groups and belonging.

\section{Bibliographical appointment system:}

Harvard-APA

Citations in the text should include between parentheses only the author's name, publication date and page number, for example:

(Quilodrán, 2001: 33).

\section{Notation about Bibliography section and Information fonts:}

Should be included at the end of the text. All references must be mentioned in the text or footnotes page.

Each reference starts with the first name or last name, then the name of the author, and then, in parentheses, the year of publication followed by a period. Examples:

Article:

Ros, Jaime (2008). "La desaceleración del crecimiento económico en México desde 1982", en Trimestre Económico, vol. 75, núm. 299, pp. 537-560. 


\section{Editorial Guidelines}

Book:

Villarreal, René (2005). Industrialización, competitividad y desequilibrio externo en México. Un enfoque macroindustrial y financiero (1929-2010), México, Fondo de Cultura Económica.

Book chapter:

Castillo, Manuel Ángel (2003). "La política de inmigración en México: un breve recuento", en Manuel Ángel Castillo, Alfredo Lattes y Jorge Santibáñez (coords.), Migración y fronteras, Tijuana, El Colegio de la Frontera Norte / Asociación Latinoamericana de Sociología / El Colegio de México, pp. $425-451$.

\section{Footnotes:}

Must be used to make additional indications, clarification or expansion of an explanation. The footnotes must be in Times New Roman, font size 10.

\section{Image typology inside text:}

Picture

Graph

Diagram

Map

Figure

All images must be numbered and mentioned in the text, should include the source image. The indications of the image: type and number of image, image title and source are written in 10 font size. In the text set as image maps, figures, graphs and charts-with the intention of not losing the formatting by the author.

\section{Equations and Formulae:}

When using equations or formulas should be used in Microsoft Word equation editor and numbered.

\section{Paper sending}

Entries must be sent to the email address: lgtz@uacj.mx. With Dr. Luis Enrique Gutiérrez Casas, editor of this publication.

Acceptance of each collaboration will depend on the evaluation of two examiners skilled in the art to be kept anonymous, like the author(s) for the same purposes. 
Publicación afiliada a la

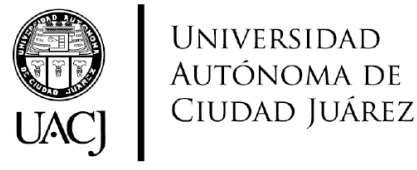

Red
RIED

Esta obra se editó y terminó de imprimir en Ciudad Juárez, Chihuahua, México 
